\title{
Knowledge about abortion law among young women in Iran
}

\author{
Lida Jarahi $^{1}$, Majid Reza Erfanian ${ }^{2}$, Rahil Mahmoudi $^{2^{*}}$ \\ ${ }^{1}$ Addiction Research Center, Faculty of Medicine, Mashhad University of Medical Sciences, Mashhad, Iran \\ ${ }^{2}$ Department of Community Medicine, Faculty of Medicine, Mashhad University of Medical Sciences, Mashhad, Iran; \\ *Corresponding Author: Mahmoudir901@mums.ac.ir
}

Received 25 November 2013; revised 30 December 2013; accepted 9 January 2014

Copyright (C) 2014 Lida Jarahi et al. This is an open access article distributed under the Creative Commons Attribution License, which permits unrestricted use, distribution, and reproduction in any medium, provided the original work is properly cited. In accordance of the Creative Commons Attribution License all Copyrights (c) 2014 are reserved for SCIRP and the owner of the intellectual property Lida Jarahi et al. All Copyright @ 2014 are guarded by law and by SCIRP as a guardian.

\section{ABSTRACT}

Young women are at risk of attempting abortion because of their tendency to delay childbearing. In legal limitation for abortion, low information about abortion laws and consequences of unsafe abortion can result in that women refer to illegal providers. This study investigated knowledge of young women about abortion laws, its complications and their consent with intentional abortion. Near to $50 \%$ of participants were not informed about national abortion legislation and its criminal law, and more than $66 \%$ of participants were not aware of unsafe abortion consequences. Of them $16 \%$ believed that abortion must not be allowed at all, and $47 \%$ expressed that legal facilities for safe abortion should be proved. High education and importance of using contraceptive were the most important variables in correlation with more information about abortion law and consequences. Providing information for women about abortion laws and complication should be more emphasized to prevent unsafe abortion especially in women with lower age and education.

\section{KEYWORDS}

\section{Abortion; Unsafe; Illegal Law; Knowledge}

\section{INTRODUCTION}

Despite that unsafe abortion is a preventable cause of maternal mortality and morbidity, this is a serious threat for young women health in developing countries [1]. Consequences of unsafe abortion are from acute com- plications like infection, hemorrhage, shock, and laceration, to long-term health consequences like adhesions, infection, infertility, anxiety, and depression [2-4]. The consequences result in significant burden on public health [5].

Countries in those where the abortion has severe legal limitation, are faced with complications of unsafe abortion in women seeking abortions regardless of prohibiting abortion laws [1]. Reviews indicate that in these countries a significant number of women who experience unwanted pregnancy, induce abortion with assistance of traditional or illegal providers [1,6].

According to the report of World Health Organization in 2008, unsafe abortion rate estimated 22 per thousand women in the world and its rate is 23 per thousand women in developing countries [7]. In Asia, the estimated number of induced abortions was 27.3 million in 2008 [8]. The incidence rate of induced abortion in Iran estimated from $1 \%-20 \%$; according to the results of one meta-analysis, induced abortion rate was about 9 per 1000 reproductive age women and induced abortion ratio was near 5 per 100 live births [9]. Despite that abortion is severely limited by law in Iran, it was estimated that 73,000 abortions per year were done [10]. One study in Tehran mentioned that more than $80 \%$ of abortions in Tehran were illegal; also birth spacing was one of the main reasons for intentional abortions [11].

Young females are more at risk of attempting abortion because of willing to delay childbearing due to multiple causes like financial cause, instability in family relationship, education or work opportunities; they may induce abortion by voluntary trauma, abuse of natural, manufactured or pharmaceutical products [2]. Evidences showed that women who had low information about the abortion laws more likely attempt to have illegal and unsafe abor- 
tions [2]. Several researches reported that in general population, knowledge about abortion law is often poor [12]. Due to consequences and burden of unsafe abortion, in this study, we investigate young women's knowledge about abortion laws, its complications and their consent about abortion.

\section{METHODS}

The data used in this research, were collected in cross sectional study on 400 women less than 30 years of age, had referred to Mashhad central laboratories for screening test before marriage in 2010, and had consent to participate in the study. Sample size was 390 women that calculated with using the formula for estimation the qualitative ratio in a society, based on prevalence of "nondisclosure about abortion law" (54\%) in the study of Becker and his colleagues [2]. Participants answered to a questionnaire about national abortion laws in Iran. Also women declared level of their consent (completely agree to strongly disagree) with possible conditions can expose women to intentional abortion. Social and demographic characteristics of participants were recorded in the questionnaire. Data entered into the Spss $_{20}$ software and analyzed by using Kruskal-Wallis, Mann-Whitney test, Spearman correlation and regression analysis.

\section{RESULTS}

One hundred forty five (36.3\%) of women were younger than 18 years old, 209 (52.3\%) were between 18 - 24 and 46 (11.4\%) had 25 - 30 years old. The mean age of the participants was $20.2 \pm 4.3$ years. Of participants 153 women (38.3\%) had a university education, and 143 (35.8\%) of them were employed. About their marriage, 265 (66.3\%) of participants had traditional marriage, 135 (33.7\%) of women had familial marriage or their marriage were through premarital friendship.

About economic status, 45 (11.3\%) of participants were in the low-income class, 337 (84.3\%) in middle-income and 18 (4.0\%) were in high-income class. Ideal number of children for 42 (10.5\%) of participants was more than 3 children, for 267 (64.3\%) was 2 children, and for 99 (24.8\%) was 1 child and 2 cases $(0.5 \%)$ was reported they tend not to have any children.

Of participants $32 \%$ were not informed about national abortion laws, 51\% of them didn't know about crime and wergild for self induced abortion and for illegal providers. Also $66.5 \%$ of participants were not aware of unsafe abortion consequences, $16 \%$ believed that abortion must not to be allowed at all, and $47 \%$ of them expressed that safe abortion conditions should be provided for women. Table 1 showed frequency of correct answer of participants to national abortion law and unsafe abortion consequences.

Regression analysis showed that high level of education and importance of using contraceptive were significantly the most important variables in correlation with greater information about abortion law and induced abortion consequences ( $\mathrm{OR}=4.8$ and 2.7 respectively).

Table 2 showed frequency of participants' agreed opinion to abortion condition in subgroups of demographic characteristic. There was positive significant correlation between importance of employment for women and consent with: perform to abortion on unwanted pregnancies ( $r=0.12, p=0.01$ ), attempt to abortions with assistance of illegal providers $(\mathrm{r}=0.11, \mathrm{p}=$ $0.04)$, abortion in sexual preference $(r=0.17, p=0.001)$, self induced abortion $(\mathrm{r}=0.14, \mathrm{p}=0.004)$, and liberal abortion law (decision for abortion is private matter and the government and its laws should not obstacle), ( $\mathrm{r}=$ $0.11, p=0.02$ ). That means agreement rate increased with the increasing importance of the employment.

There was negative significant correlation between age of woman and agreement with: perform to abortion on unwanted pregnancies $(\mathrm{r}=-0.11, \mathrm{p}=0.02)$, attempt to abortion by illegal providers $(r=-0.15, \mathrm{p}=0.003)$, abortion in sexual preference $(\mathrm{r}=-0.14, \mathrm{p}=0.006)$, and

Table 1. Frequency of correct answer of participants to national abortion law and unsafe abortion consequences.

\begin{tabular}{|c|c|c|c|c|c|}
\hline \multicolumn{2}{|c|}{ Demographic characteristic of participants } & \multirow{2}{*}{$\begin{array}{c}\begin{array}{c}\text { Abortion legal/eligible } \\
\text { provider \& places }\end{array} \\
115(79.3)\end{array}$} & \multirow{2}{*}{$\begin{array}{c}\begin{array}{c}\text { Crime and wergild } \\
\text { for woman }\end{array} \\
54(37.2)\end{array}$} & \multirow{2}{*}{$\begin{array}{c}\text { Wergild and jail for } \\
\text { illegal providers } \\
67(46.2)\end{array}$} & \multirow{2}{*}{$\begin{array}{c}\begin{array}{c}\text { Death/physical } \\
\text { disability on abortion }\end{array} \\
46(31.7)\end{array}$} \\
\hline \multirow{3}{*}{ Age group } & $<18$ years $\mathrm{N}=145$ & & & & \\
\hline & 18 - 24 years $N$ = 209 & $180(86.1)$ & $111(53.1)$ & $135(64.6)$ & $66(31.6)$ \\
\hline & 25 - 30 years $N=46$ & $39(84.8)$ & $30(65.2)$ & 34 (73.9) & $21(45.7)$ \\
\hline \multirow{2}{*}{ Education } & Academic $\mathrm{N}=153$ & 137 (89.5) & 195 (58.2) & $111(72.5)$ & $133(38.6)$ \\
\hline & Nonacademic N = 247 & $197(79.8)$ & 106 (42.9) & $125(50.6)$ & $74(30.0)$ \\
\hline \multirow{2}{*}{ Employment } & Employed N = 143 & $124(86.7)$ & $77(53.8)$ & $105(73.4)$ & $51(35.7)$ \\
\hline & Unemployed N = 257 & $210(81.7)$ & 118 (45.9) & $131(51.0)$ & 82 (31.9) \\
\hline \multirow{2}{*}{ Contraception use } & Important N = 264 & 262 (99.2) & $193(62.7)$ & $193(62.7)$ & 155 (50.3) \\
\hline & Unimportant $\mathrm{N}=136$ & $132(97.1)$ & $86(51.5)$ & $86(51.5)$ & $73(43.7)$ \\
\hline \multicolumn{2}{|c|}{ Total $=400(100 \%)$} & 334 (83.5) & 195 (48.8) & $133(33.3)$ & $236(59.0)$ \\
\hline
\end{tabular}


Table 2. Frequency of participants' agreed opinion to abortion condition in subgroups demographic characteristic.

\begin{tabular}{|c|c|c|c|c|c|c|}
\hline \multirow{2}{*}{\multicolumn{2}{|c|}{ Demographic characteristic of participants }} & \multicolumn{5}{|c|}{ Frequency of participants' agreed opinion to abortion condition $\mathrm{N}$ (\%) } \\
\hline & & \multirow{2}{*}{$\begin{array}{c}\begin{array}{c}\text { In unwanted } \\
\text { pregnancy }\end{array} \\
48(33.1)\end{array}$} & \multirow{2}{*}{$\begin{array}{c}\begin{array}{c}\text { Using illegal } \\
\text { providers }\end{array} \\
24(16.6)\end{array}$} & \multirow{2}{*}{$\begin{array}{c}\begin{array}{c}\text { In sexual } \\
\text { preference }\end{array} \\
17(11.7)\end{array}$} & \multirow{2}{*}{$\begin{array}{c}\begin{array}{c}\text { Self induced } \\
\text { abortion }\end{array} \\
35(24.1)\end{array}$} & \multirow{2}{*}{$\begin{array}{c}\text { Liberal laws } \\
50(34.5)\end{array}$} \\
\hline \multirow{3}{*}{ Age group } & $<18$ years $\mathrm{N}=145$ & & & & & \\
\hline & $18-24$ years $N=209$ & $46(22.0)$ & $9(4.3)$ & $9(4.3)$ & $20(9.6)$ & $54(25.8)$ \\
\hline & $24-30$ years $N=46$ & $9(19.6)$ & $5(10.9)$ & $3(6.5)$ & $5(10.9)$ & $13(28.3)$ \\
\hline \multirow[t]{2}{*}{ Education } & Academic $\mathrm{N}=153$ & $24(15.7)$ & $4(2.6)$ & $2(1.3)$ & $13(8.5)$ & $32(20.9)$ \\
\hline & Nonacademic $\mathrm{N}=247$ & $79(32.0)$ & $34(13.8)$ & $27(10.9)$ & $47(19.1)$ & $85(34.4)$ \\
\hline \multirow{2}{*}{ Employment } & Employed $\mathrm{N}=143$ & $29(20.3)$ & $5(3.5)$ & $2(1.4)$ & $13(9.1)$ & $33(23.1)$ \\
\hline & Unemployed N = 257 & $74(28.8)$ & $33(12.8)$ & 27 (10.5) & 47 (18.3) & $84(32.7)$ \\
\hline \multirow{2}{*}{ Contraception use } & Important N = 264 & $59(22.3)$ & $14(5.3)$ & $8(3.0)$ & $24(9.1)$ & $66(25.0)$ \\
\hline & Unimportant $\mathrm{N}=136$ & $44(32.4)$ & $24(17.6)$ & $21(15.4)$ & $36(26.5)$ & $51(37.5)$ \\
\hline \multicolumn{2}{|c|}{ Total $=400(100 \%)$} & $103(25.8)$ & $38(9.5)$ & $29(7.3)$ & $60(15.0)$ & $117(29.3)$ \\
\hline
\end{tabular}

self induced abortion by using herbal medicines or by trauma $(\mathrm{r}=-0.19, \mathrm{p}<0.001)$. In addition there was negative significant correlation between educational level of women and consent with: attempt to abortion by illegal abortion providers $(\mathrm{r}=-0.16, \mathrm{p}<0.001)$, abortion in sexual preference $(r=-0.22, p<0.001)$, and self induced abortion ( $\mathrm{r}=-0.17, \mathrm{p}<0.001)$. This showed that consent to the abortion on these conditions, decreased with increasing age and education level.

It was observed that there was negative significant correlation between women's employment and consent with: perform to abortion on unwanted pregnancies $(\mathrm{r}=$ $-0.17, p=0.01)$, abortion in sexual preference $(r=-0.12$, $p=0.02)$, and self induced abortion $(r=-0 / 11, p=0.02)$. This means that being employed was associated with lower agreement to abortion. Moreover there was a negative significant correlation between the importance of using contraceptive for women and consent with: attempt to abortion by illegal abortion providers $(\mathrm{r}=-0.22$, $\mathrm{p}<0.001)$, abortion in sexual preference $(\mathrm{r}=-0.19, \mathrm{p}<$ $0.001)$, and self induced abortion $(r=-0.12, p=0.01)$. This means that consent to abortion, decreased with the increasing importance of the contraceptive use for women. However there was no significant correlation between the ideal number of children for participants, also economic class of participants with consent to attempted abortion, in none of possible condition were in questionnaire $(\mathrm{p}>0.05)$.

\section{DISCUSSION}

This study showed that knowledge about abortion law among young women in Iran was inadequate. Researchers reported that in general population, knowledge about abortion law is often poor [12]. Although significant differences have been reported in various countries, most of developing country was reported inadequate knowledge in female.
In a study about knowledge of female student in Nigeria on induced abortion and its complications the majority of female students (83.3\%) had good knowledge about unsafe abortion risks; also there was seen direct relationship between level of female education and their knowledge about complications of abortion [7]. Survey on knowledge of women and risk factors of induced abortion in Ethiopia found that $75 \%$ of participants knew about complications of abortion, also there was a decrease in the number of mothers who had induced abortion with increasing their age, number of pregnancies, and level of education of the study subjects [13]. Assessment of Knowledge about abortion law in Mexican youth showed that more than half of participants did not know the legal aspects of abortion and the most of them believed that abortions were totally illegal, well as with the increase of educational level, participants' knowledge about legal abortions was increased [2]. One survey in Sri Lanka reported about $90 \%$ of women were seeking termination of pregnancy did not know that induced abortion is illegal and $96 \%$ of them were not aware of adverse effects of abortion [14].

In this study level of education and using contraception were the most important variables in correlation with level of information about abortion law and induced abortion consequences. There was negative correlation between agreement with intentional abortion and age, educational level, employment, importance of using contraceptive for women, though there was positive significant correlation between the importance of employment for women and consent with perform to abortion. In another study in Iran found that poor, young and overcrowded families were the main groups that seek abortion, and unwanted pregnancies and low social status were the most reason for abortion [5]. In research about determinants of induced abortion in India mentioned that socioeconomic status is associated with abortion and increasing parity had positively correlated with abortion 
[15].

One study that described psychological consequences of abortion in Muslim women, reported that depression and anxiety was reported more in women who believed abortion is contrary to the Islamic laws and in whom attempt to abortion with not too passable reasons [16]. Assessment of intervention programs for improvement of female's knowledge about abortion law in India indicated that such programs were useful and had significant effects on changing knowledge and behavior of aim population [17]. Therefore based on outcomes of low level of knowledge and effectiveness of intervention programs, suggested such educational programs included in the care package of women.

\section{CONCLUSION}

It is important to inform women about abortion laws and its complication; and for prevention of unsafe abortion it should be more emphasized, especially in society that abortion is restricted and in contrast of public believes and in women with lower, lower age and lower education.

\section{REFERENCES}

[1] Warriner, I.K. and Shah, I.H. (2006) Preventing unsafe abortion a research and action. Guttmacher Institute, New York.

[2] Becker, D., Garcia, S.G. and Larsen, U. (2002) Knowledge and opinions about abortion law among Mexican youth. International Family Planning Perspectives, 28, 205-213. http://dx.doi.org/10.2307/3088223

[3] Shamshiri Milani, H., Pourreza, A. and Akbari, F. (2010) Knowledge and attitudes of a number of iranian policymakers towards abortion. Journal of Reproduction and Infertility, 11, 189-195.

[4] Makinwa-Adebusoye, P., Singh, S. and Audam, S. (1997) Nigerian health professionals' perceptions about abortion practice. International Family Planning Perspectives, 23, 155-161. http://dx.doi.org/10.2307/2950839

[5] Shamshiri Milani, H. (2005) Mother's rights to life: A medical approach to abortion. Journal of Reproduction and Infertility, 6, 457-464.

[6] Singh, S., Wulf, D. and Jones, H. (1997) Health professionals' perceptions about abortion in south central and southeast Asia. International Family Planning Perspec- tives, 23, 59-67. http://dx.doi.org/10.2307/2950825

[7] Cadmus, E. and Owoaje, E. (2011) Knowledge about complications and practice of abortion among female undergraduates in the university of Ibadan, Nigeria. Annals of Ibadan Postgraduate Medicine Journal, 9, 19-23.

[8] Sedgh, G., Singh, S., Shah, I.H., Ahman, E., Henshaw, S.K. and Bankole, A. (2012) Induced abortion: Incidence and trends worldwide from 1995 to 2008. The Lancet, 379, 625-632. http://dx.doi.org/10.1016/S0140-6736(11)61786-8

[9] Motaghi, Z., Poorolajal, J., Keramat, A., Shariati, M., Yunesian, M. and Masoumi, S.Z. (2013) Induced Abortion Rate in Iran: A Meta-analysis. Archives of Iranian Medicine, 16, 594-598.

[10] Erfani, A. and McQuillan, K. (2008) Rates of induced abortion in Iran: the roles of contraceptive use and religiosity. Studies in Family Planning, 39, 111-122. http://dx.doi.org/10.1111/j.1728-4465.2008.00158.x

[11] Erfani, A. and Kazemipoor, Sh. (2010) Abortion rates and reasons for abortion in the city of Tehran. Journal of Population Association of Iran, 4, 63-84.

[12] Berer, M. (2000) Making abortions safe: A matter of good public health policy and practice. Bulletin of the World Health Organization, 78, 580-592.

[13] Senbeto, E., Alene, G.D., Abesto, N. and Yeneneh, H. (2005) Prevalence and associated risk factors of induce abortion in North West Ethiopia. The Ethiopian Journal of Health Development, 19, 37-44. http://dx.doi.org/10.4314/ejhd.v19i1.9969

[14] Perera, J., de Silva, T. and Gange, H. (2004) Knowledge, behavior and attitudes on induced abortion and family planning among Sri Lankan women seeking termination of pregnancy. Ceylon Medical Journal, 49, 14-17.

[15] Elul, B. (2011) Determinants of induced abortion: An analysis of individual, household and contextual factors in Rajasthan, India. Journal of Biosocial Science, 43, 117. http://dx.doi.org/10.1017/S0021932010000490

[16] Wiebe, E., Najafi, R., Soheil, N. and Kamani, A. (2011) Muslim women having abortions in Canada: Attitudes, beliefs, and experiences. Canadian Family Physician, 57, 134-138.

[17] Banerjee, S.K., Andersen, K.L., Warvadekar, J. and Pearson, E. (2013) Effectiveness of a behavior change communication intervention to improve knowledge and perceptions about abortion in Bihar and Jharkhand, India. International Perspectives on Sexual and Reproductive Health, 39, 142-151. http://dx.doi.org/10.1363/3914213 